IZA DP No. 8326

Skilled Immigrants' Contribution to

Productive Efficiency

Daehoon Nahm

Massimiliano Tani

July 2014 


\title{
Skilled Immigrants' Contribution to Productive Efficiency
}

\author{
Daehoon Nahm \\ Macquarie University \\ Massimiliano Tani \\ UNSW Canberra \\ and IZA
}
Discussion Paper No. 8326
July 2014

\author{
IZA \\ P.O. Box 7240 \\ 53072 Bonn \\ Germany \\ Phone: +49-228-3894-0 \\ Fax: +49-228-3894-180 \\ E-mail: iza@iza.org
}

Any opinions expressed here are those of the author(s) and not those of IZA. Research published in this series may include views on policy, but the institute itself takes no institutional policy positions. The IZA research network is committed to the IZA Guiding Principles of Research Integrity.

The Institute for the Study of Labor (IZA) in Bonn is a local and virtual international research center and a place of communication between science, politics and business. IZA is an independent nonprofit organization supported by Deutsche Post Foundation. The center is associated with the University of Bonn and offers a stimulating research environment through its international network, workshops and conferences, data service, project support, research visits and doctoral program. IZA engages in (i) original and internationally competitive research in all fields of labor economics, (ii) development of policy concepts, and (iii) dissemination of research results and concepts to the interested public.

IZA Discussion Papers often represent preliminary work and are circulated to encourage discussion. Citation of such a paper should account for its provisional character. A revised version may be available directly from the author. 
IZA Discussion Paper No. 8326

July 2014

\section{ABSTRACT}

\section{Skilled Immigrants' Contribution to Productive Efficiency}

This paper studies whether skilled migrants contribute to the host country's 'productive efficiency' (Farrell, 1957) using input-output and immigration sectoral data for seven industries in twelve countries during the period 1999-2001. We find that skilled migrants contribute positively to a country's productive efficiency with the exception of the finance sector. The results broadly support the adoption of skill-biased migration policies.

JEL Classification: D24, F2, F66, J6, J24

Keywords: highly skilled migration, human capital, productive efficiency

Corresponding author:

Massimiliano Tani

IZA

P.O. Box 7240

D-53072 Bonn

Germany

E-mail: tani@iza.org

* We thank Anastasia Nadykto for excellent research assistance and Macquarie University for financial support (Start Grant scheme). 


\section{Introduction}

One of the current controversies surrounding immigration policy is the usefulness of skill-biased immigration programmes like those in force in Canada, Australia, and New Zealand, which select 'skilled' immigrants on the basis of a points system ${ }^{1}$ (Borjas, 1991; Beach et al, 2007). In such programmes, 'skilled' includes a composite of formal education typically at or above Bachelor's degree, relevant work experience, minimum knowledge of the host country’s language, and age. Skilled migration streams contrast with traditional family reunification programmes, which admit immigrants on the basis of kinship with the host country's residents, and humanitarian programmes of relocation of asylum seekers (Miller, 1999; Belot and Hatton, 2012).

The rationale for implementing a skill-biased immigration policy is that skilled migrants are more likely to find employment after admission to the host country, are more mobile, and contribute faster to the public finance than other types of immigrants. ${ }^{2}$ Indeed, research on the labour market outcomes of recent immigrants to Canada, Australia, and New Zealand provides support for skill-biased migration (Green and Green, 1995; Winkelmann, 1999; Antecol et al 2003), fuelling the debate on its usefulness in countries that currently do not have one, like the United States, and where large unregulated immigration has occurred, or is feared, as in the European Union (Zimmermann et al, 2000).

One under-researched angle of existing analyses of skill-biased immigration policies is the extent to which skilled migrants contribute to the efficient use of productive

\footnotetext{
${ }^{1}$ The point-based immigration system started in Canada in 1962 and later adopted in Australia and New Zealand and in a plethora of other destination countries in more recent times, including the UK, the Czech Republic, Denmark, Japan, Hong Kong, Singapore, and Germany amongst others.

${ }^{2}$ Studies that analyse the effect of migrants in general, as opposed to skilled migrants, often find a negative effect on productivity; see for example, Kangasniemi et al. (2012) for the UK and Spain, and Paserman (2013) for Israel.
} 
inputs for the host country. Existing work tends to analyse the effects of migration on productivity resulting from the reallocation of human capital between places of origin and destination. By migrating, individuals unable to use their skills at home do so in the host country, leading to increased production there ${ }^{3}$. For example, the literature on skilled migration highlights the contribution of these migrants to innovation activity and the development of new technology in the United States (Hunt and GauthierLoiselle, 2008). Similar work for the European Union suggests that such contribution is evident only for non-EU skilled migrants, who are subjected to some form of screening unlike their EU counterparts (Huber et al, 2010).

The increased productivity resulting from migration however captures only part of migrants' overall contribution to the host country’s economy. Migrants' skills are often under-utilised by host country employers, even in countries applying a selective immigration policy, as emerging from the study of immigrants' level of experience and formal education vis-à-vis the jobs they fill (Dolton and Vignoles, 2000; Kler, 2007). This implies a wastage of resources that is detrimental to the country of origin, which subsidises emigrants' formal education, and the host country where such human capital earns a lower rate of return than what is achieved by its native equivalents.

The total effect of skilled migration on the host country's economy can nevertheless be captured by a weighted measure of migrants' contribution to productivity and level of utilisation in the labour market known as 'productive efficiency'. Such approach measures how close an economy is to a benchmark production possibility frontier that uses all resources efficiently: namely when inputs are used in their lowest possible amounts for the production of an output.

\footnotetext{
${ }^{3}$ Migration also improves conditions in the host country via higher capital/labour ratios and/or remittance inflows.
} 
We apply the productive efficiency approach to a number of countries that differ in immigration policy towards skilled migration: some have established skill-biased migration policies, like Australia, Canada and New Zealand; others have a much narrower approach to skilled migration (e.g. the United States). Some have only recently introduced targeted programmes to attract specific skilled workers (eg. the Czech Republic and Denmark).

Our analysis covers seven industries in twelve countries for the period 1999-2001, and uses input and output data from the EU-KLEMS database and the single crosssectional information on skilled migration data from the OECD Stan database. Given the limited availability of data over time we construct a single cross-sectional dataset, and measure relative productive efficiency at a given point in time ${ }^{4}$.

Our results suggest that skilled migrants contribute positively to a country's productive efficiency in all sectors aside from Finance, for which we offer an interpretation, and they broadly support the introduction of skill-biased migration policies. They provide additional insights into the various dimensions in which skilled migration contributes to a country's economy and offers new information to policymakers debating the advantages and limitations of introducing skill-biased immigration policies.

The rest of the paper is organised as follows: Section 2 introduces the concept of productive efficiency and the methodology. Section 3 presents the data. Section 4 discusses the results. Section 5 concludes and highlights implications for policy.

\footnotetext{
${ }^{4}$ We only have one year of information about the proportions of skilled migrant workers. Constructing a single cross-sectional dataset prevents us from using panel data approaches measuring total productivity as the result of changes attributable to a change in the production technology as well as changes in productive efficiency, as occurring when there is a shift of the efficiency frontier, which usually occurs over time. A measure of total productivity such as the multi-factor productivity (MFP), which is based on the growth-accounting method, is inappropriate for a comparison of productivity levels across countries and industries at a given point in time (see for example Inklaar and Timmer, 2008).
} 


\section{Measurement of Productive Efficiency}

Productive efficiency aims to measure the minimum amount of inputs required to produce a certain quantity of output. The literature on productive efficiency stems from the empirical work of Farrell (1957), who developed a method to estimate the productive efficiency of a country. Over time, the estimation of production function frontiers has been carried out using either deterministic methods or stochastic techniques. Deterministic methods, which include methodologies known as data envelopment analysis (DEA) of Charnes et al. (1978) and the free disposal hull (FDH) of Deprins et al. (1984), apply linear programming techniques to construct a frontier by using a piecewise linear envelope that connects the best performers (e.g. sectorcountry combinations that receive the highest efficiency scores). The main advantage of this approach is the small number of restrictions imposed on the properties of the production technology. Its main limitation is not disentangling white noise from inefficiency measures.

In the stochastic approach, random shocks are included to cater for deviations from the production frontier, and inputs for productions are distinguished from other conditions that nevertheless have an influence on the efficient use of resources, like environment and institutions.

To ascertain the contribution of skilled migrants to a country's productive efficiency we apply the DEA method, and define a measure of productive efficiency that is comparable across countries and sectors. The DEA method is preferred to the stochastic frontier method in the present case because the group of decision-making units (DMUs) comprises various industries in different countries with potentially different production technologies, making it inappropriate to specify them using a specific functional form. We consider a sector of a country as a single DMU that produces its gross output using various inputs. Some sectors may be more efficient in 
utilizing the available technology and produce more output than others using the same level of inputs. Some may be less efficient and produce less than others. In the spirit of Farrell (1957), we measure the productive efficiency of a sector of a country by comparing its actual gross output with the maximum gross output that can be produced using the same levels of inputs. This can be facilitated via the output distance, which represents the proportion by which the actual output of a country could be increased without changing the levels of inputs if the sector were fully efficient under the available technology.

The output distance function is defined as

$$
\mathrm{D}(\mathrm{x}, \mathrm{y}: \mathrm{T})=\max _{\delta}\{\delta:(\mathrm{x}, \delta \mathrm{y}) \in \mathrm{T}\}
$$

where $\mathrm{y} \in \mathrm{R}_{+}$is gross output, $\mathrm{x} \in \mathrm{R}_{+}^{\mathrm{N}}$ is an input vector, and $\mathrm{T} \subset \mathrm{R}_{+}^{\mathrm{N}+1}$ is the set of input-output mixes that are feasible under the available technology, namely $\mathrm{T}=$ $\{(\mathrm{x}, \mathrm{y})$ : $\mathrm{x}$ can produce $\mathrm{y}\}$. Under regular conditions, $\mathrm{D}(\mathrm{x}, \mathrm{y})$ is greater than or equal to one. For a sector that is efficient, the output distance will be one because the actual level of output is the maximum that can be produced without changing inputs. For an inefficient sector, on the other hand, the output distance will be larger than one implying that output can be inflated without increasing inputs. Therefore, a measure of productive efficiency can be defined as

$$
\operatorname{PE}(x, y: T)=1 / D(x, y: T)
$$

which is bounded between zero and one. PE will be one for efficient sectors and less than one for inefficient sectors. For example, a PE of 0.8 implies that the sector is only $80 \%$ efficient compared with the best performing sector and hence output could be increased by up to $25 \%$ (=[1-0.8]/0.8) given the same levels of inputs. 
We measure distances using the DEA method under the assumption of constant returns to scale (CRS). ${ }^{5}$ The linear-programming (LP) model for a sector of a country (DMU k) can be written as:

$\operatorname{Max} . \quad \delta$

$$
\begin{array}{ll}
\text { s.t. } & \delta y^{\mathrm{k}}-\mathrm{Y} \lambda \leq 0 \\
& -\mathrm{x}^{\mathrm{k}}+\mathrm{X} \lambda \leq 0 \\
& \delta, \lambda \geq 0 \quad \text { for } \mathrm{k}=1, \ldots, \mathrm{K}
\end{array}
$$

where $\delta$ is the output distance, $\mathrm{y}^{\mathrm{k}}$ is DMU k's output, $\mathrm{x}^{\mathrm{k}}$ is an $(\mathrm{N} \times 1)$ vector of DMU k's inputs, $\mathrm{Y}$ and $\mathrm{X}$ are $(1 \times \mathrm{K})$ and $(\mathrm{N} \times \mathrm{K})$ matrices of outputs and inputs of all $\mathrm{K}$ DMUs respectively, and $\lambda$ is a $(\mathrm{K} \times 1)$ vector of intensity coefficients. This LP problem involves finding by how much DMU k can increase its output without changing its inputs, subject to the constraint that it cannot produce more than the maximum level implied by the frontier formed by the best performers in the group of K DMUs. ${ }^{6}$

\section{Data}

The main source of data for measures of productivity by sector is the EU KLEMS database $^{7}$, while measures of the national stocks of skilled migrants by industry are drawn from the OECD Stan database.

Following Jorgenson and Timmer (2011), we group the 31 industries in the EU KLEMS's alternative aggregation scheme into seven sectors: Electrical Machinery, Post and Communication Services (ELECOM); Total Manufacturing, excluding Electrical (MexElec); Other Production (OtherG); Distribution (DISTRB); Finance

\footnotetext{
5 The countries included in the present study are relatively homogenous in terms of the level of economic development, and hence they are expected to have similar scale elasticities.

${ }^{6}$ Under the assumption of CRS, both output-oriented and input-oriented approaches result in identical efficiency measures because the input distance is simply the reciprocal of the output distance; see Proposition (2.1.26) of Färe and Primont (1995).

${ }^{7}$ See the EU KLEMS website euklems.net for the database, and Timmer et al. (2007) for the definitions and descriptions of the series.
} 
and Business, except Real Estate (FINBU); Personal Services (PERS); and NonMarket Services (NONMAR).

Each sector produces a single output using intermediate, labor, ICT capital, and NonICT capital inputs. The quantity of output is defined as the real gross output of the sector (GO), while the quantity of intermediate input is defined as real expenditure on intermediate inputs (II). Labor input is defined as the total number of hours worked by persons engaged (H_EMP), and ICT and Non-ICT capital inputs are defined as real fixed capital stocks (K_ICT and K_NonICT).

All these series except H_EMP in the EU KLEMS database are in local currency values. To convert the nominal values to volumes that are comparable across countries as well as over time, the GO is divided by the PPP exchange rate (PPP, local currency per US\$) and then by the US gross output price index (US_GO_P), while the II is divided by the PPP and then by the US intermediate input price index (US_II_P). K_ICT and K_NonICT are presented in local currency's 1995 price in the EU KLEMS database. These series are reverted to current values first and then converted to real volumes by dividing by the PPP and the US GDP deflator (Table A.1 in the Appendix summarises additional details and the definitions of the variables).

The group of countries included in the analysis is constrained by the availability of data on the capital input variables and migrant workers (to be used in the regression analysis in the next section), leaving a group of 12 countries comprising of Australia (AUS), Austria (AUT), the Czech Republic (CZE), Denmark (DEN), Finland (FIN), Italy (ITA), the Netherlands (NET), Portugal (POR), Spain (SPA), Sweden (SWE), the United Kingdom (UK), and the United States (US). Our sample data set includes 3 yearly observations over 1999 - 2001 of the seven sectors of each of the 12 countries. Some descriptive statistics of the productivity variables used for the DEA analysis are 
presented in Table 1, while more detailed 3-year averages for individual sectors and countries are in Table A.2.

Table 1: Descriptive Statistics of the Data for DEA Analysis*

\begin{tabular}{|c|c|c|c|c|c|c|c|c|}
\hline & $\mathrm{ALL}^{\#}$ & ELECOM & MexElec & OtherG & DISTRB & FINBU & PERS & NONMAR \\
\hline \multicolumn{7}{|l|}{ Output } & \multicolumn{2}{|c|}{ US\$m (2000) } \\
\hline average & $2,209,050$ & 171,689 & 503,968 & 225,519 & 352,556 & 348,051 & 140,156 & 463,164 \\
\hline s.d. & $4,448,395$ & 378,242 & 923,286 & 378,302 & 640,181 & 783,188 & 275,501 & $1,070,561$ \\
\hline c.v. & 2.01 & 2.20 & 1.83 & 1.68 & 1.82 & 2.25 & 1.97 & 2.31 \\
\hline \multicolumn{7}{|c|}{ Intermediate Input } & \multicolumn{2}{|c|}{ US\$m (2000) } \\
\hline average & $1,094,862$ & 85,314 & 344,724 & 125,293 & 146,331 & 157,433 & 70,204 & 158,718 \\
\hline s.d. & $2,065,207$ & 177,936 & 608,808 & 192,444 & 233,465 & 337,324 & 139,037 & 378,188 \\
\hline c.v. & 1.89 & 2.09 & 1.77 & 1.54 & 1.60 & 2.14 & 1.98 & 2.38 \\
\hline \multicolumn{7}{|l|}{ Labour } & \multicolumn{2}{|c|}{ million hours } \\
\hline average & 38,088 & 1,449 & 5,479 & 4,457 & \begin{tabular}{l|l|}
7,696 \\
\end{tabular} & 5,870 & 4,183 & 8,953 \\
\hline s.d. & 74,288 & 3,077 & 9,553 & 6,985 & 14,392 & 12,690 & 7,968 & 19,812 \\
\hline c.v. & 1.95 & 2.12 & 1.74 & 1.57 & 1.87 & 2.16 & 1.91 & 2.21 \\
\hline \multicolumn{7}{|c|}{ ICT Capital } & \multicolumn{2}{|c|}{ US\$m (2000) } \\
\hline average & 255,727 & 59,381 & 25,213 & 11,084 & 44,495 & 76,283 & 7,619 & 31,652 \\
\hline s.d. & 599,457 & 148,071 & 54,298 & 25,278 & 94,125 & 194,535 & 9,707 & 75,423 \\
\hline c.v. & 2.34 & 2.49 & 2.15 & 2.28 & 2.12 & 2.55 & 1.27 & 2.38 \\
\hline \multicolumn{7}{|c|}{ NonICT Capital } & \multicolumn{2}{|c|}{ US\$m (2000) } \\
\hline average & $3,321,193$ & 105,247 & 258,833 & 354,330 & 283,481 & 321,231 & 100,247 & $1,901,339$ \\
\hline s.d. & $6,185,266$ & 245,125 & 406,648 & 654,527 & 451,209 & 704,743 & 161,405 & $4,008,128$ \\
\hline c.v. & 1.86 & 2.33 & 1.57 & 1.85 & 1.59 & 2.19 & 1.61 & 2.11 \\
\hline
\end{tabular}

*: Averages of 12 countries. Each country's figures are averages over 3 years, 1999, 2000, and 2001. The largest and the smallest sectors are highlighted.

\#: The figures for ALL sectors are slightly different from the sum of sectoral figures because price indices (GO_P) used in the conversion of nominal values to real volumes are different from sector to sector. (Source of the raw data: EU KLEMS)

The relatively high coefficient of variation (c.v.) of real output for the whole economy, 2.01, reflects huge differences in the sizes of economies with the largest economy, that of the US, being more than 70 times that of Finland, the smallest in the group. With exceptions of Australia, Denmark and US, the largest sector of a country in terms of size of output is the Manufacturing (excluding Electrical) sector. For both Australia and Denmark, the largest sector is the Distribution sector, while for the US it is the Non-Market sector, which is not surprising as it includes defence (Table A.2). For all countries, the biggest user of intermediate input is the Manufacturing sector. When it comes to the use of labour, it is either the Distribution sector or the NonMarket sector for most countries. The input that has the highest variation in quantity across the countries is ICT-capital, with the coefficient of variation being greater than 2 for all sectors but the Personal Services sector. In most countries, the Finance \& 
Business and the Distribution sectors use the most ICT-capital, but in Austria, the Czech Republic and the UK it is the Electrical and Communications sector that does. Apart from the Non-Market services sector, the Other Production and the Distribution sectors have the largest Non-ICT capital stock in all countries but in Italy. In Italy, the Finance and Business Services sector has more Non-ICT capital stock than any other sectors including the Non-Market Services sector. ${ }^{8}$

Table 2 presents data on skilled migrant and native workers for each country. The observations were made only once in the year 2000. In the empirical analysis, to exploit the three-year span for which we have data, we will assume that the proportion of migrant workers during 1999-2001 remains unchanged relative to the 2000 level.

Table 2: Descriptive Statistics of the Immigrants Data

\begin{tabular}{|c|ccc|}
\hline Country & $\begin{array}{c}\text { Skilled Foreigners/ } \\
\text { Total Foreigners }\end{array}$ & $\begin{array}{c}\text { Skilled Natives/ Total } \\
\text { Natives }\end{array}$ & $\begin{array}{c}\text { Skilled Foreigners/ } \\
\text { Total Skilled }\end{array}$ \\
\hline AUS & $35.7 \%$ & $26.5 \%$ & $29.8 \%$ \\
AUT & $13.6 \%$ & $15.4 \%$ & $12.4 \%$ \\
CZE & $22.8 \%$ & $15.5 \%$ & $5.7 \%$ \\
DEN & $28.7 \%$ & $24.5 \%$ & $6.1 \%$ \\
FIN & $24.9 \%$ & $34.1 \%$ & $1.6 \%$ \\
ITA & $16.5 \%$ & $15.0 \%$ & $5.1 \%$ \\
NET & $25.3 \%$ & $24.7 \%$ & $8.5 \%$ \\
POR & $23.7 \%$ & $12.0 \%$ & $15.5 \%$ \\
SPA & $22.8 \%$ & $25.8 \%$ & $6.0 \%$ \\
SWE & $28.9 \%$ & $27.1 \%$ & $11.2 \%$ \\
UK & $44.1 \%$ & $24.9 \%$ & $14.5 \%$ \\
US & $31.9 \%$ & $34.9 \%$ & $12.3 \%$ \\
\hline
\end{tabular}

Skilled foreigners constitute about a quarter to a third of the stock of immigrant workers available in each of the twelve countries. The only exceptions are Austria, where they constitute $13.6 \%$ and Italy (16.5\%). The highest proportions of skilled migrants are in English-speaking countries, topped by the UK, then Australia and the US, perhaps reflecting the language advantage of English, which is one of the most commonly spoken languages in the world, as these countries’ official language. They are followed by the Nordic countries (Sweden, Finland, and Denmark), whose official

\footnotetext{
${ }^{8}$ The capital stock for the Finance and Business Services sector in Italy is certainly an outlier, which could be a result of mis-measurement due to the complexity of the classification and measurement of
} 
languages are also similar and which have an established policy of openness to regional labour movements across them. The countries with the lowest proportion of skilled foreigners are traditional emigration countries, which have experienced net immigration flows only since the mid-1990s (Italy, Spain, Portugal, and the Czech Republic).

The proportion of skilled workers amongst immigrants tends to be higher than the corresponding proportion amongst natives, with the exception of Austria, Finland, Spain, and the US. Immigrants account for a third of the overall stock of skilled labour in the case of Australia - the only host country with an established skill-biased immigration policy. Austria, Sweden, Portugal, the UK, and the US have broadly similar skilled shares of immigrants in their skilled workforce (11\%-15\%). In contrast, immigrants account for only a relatively small fraction of the skilled workforce in Finland (the lowest, with only 1.6\%), the Czech Republic, Italy, Spain, and Denmark (1\%-5\%). Table 3 presents the proportion of immigrants amongst skilled labour for each sector of the countries. The top left cell in the Table informs that immigrants account for $44.5 \%$ of skilled workers in Electrical Machinery, Post and Communication Services (Elecom) in Australia (AUS).

Table 3: Immigrants' Share of Skilled Labour in the Data Used

\begin{tabular}{|c|rrrrrrr|}
\hline Country & ELECOM & MexElec & OtherG & \multicolumn{1}{c}{ DISTRB } & \multicolumn{1}{r|}{ FINBU } & PERS & NONMAR \\
\hline AUS & $44.5 \%$ & $38.0 \%$ & $25.9 \%$ & $36.6 \%$ & $33.1 \%$ & $31.3 \%$ & $24.9 \%$ \\
AUT & $15.5 \%$ & $11.0 \%$ & $6.9 \%$ & $17.5 \%$ & $14.5 \%$ & $21.7 \%$ & $9.7 \%$ \\
CZE & $5.9 \%$ & $5.8 \%$ & $4.0 \%$ & $10.7 \%$ & $5.7 \%$ & $9.2 \%$ & $4.6 \%$ \\
DEN & $8.1 \%$ & $7.5 \%$ & $5.4 \%$ & $9.0 \%$ & $7.2 \%$ & $9.9 \%$ & $4.7 \%$ \\
FIN & $2.2 \%$ & $1.5 \%$ & $0.9 \%$ & $1.8 \%$ & $1.5 \%$ & $2.1 \%$ & $1.5 \%$ \\
ITA & & & $7.7 \%$ & $9.5 \%$ & $2.8 \%$ & $17.7 \%$ & $3.6 \%$ \\
NET & $12.1 \%$ & $9.0 \%$ & $6.1 \%$ & $15.1 \%$ & $8.0 \%$ & $10.2 \%$ & $7.3 \%$ \\
POR & $15.7 \%$ & $17.1 \%$ & $25.0 \%$ & $17.5 \%$ & $14.7 \%$ & $23.6 \%$ & $13.8 \%$ \\
SPA & $5.8 \%$ & $5.4 \%$ & $8.3 \%$ & $6.3 \%$ & $5.4 \%$ & $15.5 \%$ & $4.6 \%$ \\
SWE & $15.2 \%$ & $14.3 \%$ & $8.5 \%$ & $16.4 \%$ & $11.1 \%$ & $14.0 \%$ & $9.8 \%$ \\
UK & $15.6 \%$ & $11.1 \%$ & $9.1 \%$ & $17.8 \%$ & $17.0 \%$ & $17.6 \%$ & $13.1 \%$ \\
US & & & $9.7 \%$ & $14.2 \%$ & $12.7 \%$ & $14.6 \%$ & $11.2 \%$ \\
\hline
\end{tabular}


In general, skilled immigrant workers concentrate in Distribution services and Manufacturing, especially in countries that traditionally import immigrant labour (e.g. English-speaking countries). In countries where immigration is more recent, skilled immigrants seem to find employment particularly in Personal Services (Austria, Italy, Portugal, Spain).

\section{$4 \quad$ Empirical Results}

The empirical analysis consists of two stages. First, we estimate each country-sector's productive efficiency. For the measurement of productive efficiency, each sector of a country in each year is treated as a single DMU whose performance is measured against a common technological frontier consisting of all sectors of all countries in all three years. Hence, there are 252 DMUs ( 7 sectors x 12 countries x 3 years) to form a frontier in a 5-dimensional space (one output plus four inputs).

Table 4 presents productive efficiency scores, defined by (2), averaged over the three years. The best performer in terms of the overall average score is the U.S. (0.925), followed by Austria (0.911). The U.S. has the highest score for the Distribution sector and the second highest scores for the Electrical \& Communication sector, the Finance \& Business sector, and the Personal Services sector. Austria does not have the highest score for any sector, but it performs well consistently across all sectors. Finland has the highest scores for the Electrical \& Communication sector and the Finance \& Business sector, while the Netherlands, Portugal, Spain and Italy are the best performers in the Manufacturing, the Other Production, the Personal Services, and the Non-Market sectors respectively.

At the other end of the spectrum is the Czech Republic whose scores are the lowest for all sectors, ranging from 78\% (NONMAR) to 95\% (MexElec) of the next lowest scores within the corresponding sectors. These low efficiency scores are consistent with the input-output figures in Table A.2. In terms of output, the Czech Republic is 
the fourth smallest country after Finland, Denmark and Portugal. However, the country uses more intermediate, labour and ICT-capital inputs than five other countries, including Austria and Sweden who produce more outputs. This result is not surprising given that the Czech Republic is the only country in the group that is a former communist country, and hence might have had limited access to new technology and production systems. ${ }^{9}$

Across sectors, the most efficiently operated sector is the Manufacturing sector (0.933), while the least efficient sector is the Non-Market Services sector (0.792). It appears natural that the Non-Market sector is the least efficient, but that the Electrical \& Communication sector and the Finance \& Business sector perform less efficiently than the Manufacturing sector is somewhat surprising. In fact, for some countries the Finance \& Business sector is more efficient than the Manufacturing sector. However, the poor performance of the former relative to the latter in the Czech Republic, Italy, the Netherlands, Portugal and the UK drives the lower average score.

Table 4: Productive Efficiency Scores (average over three years)

\begin{tabular}{|c|ccccccc|c|}
\hline Country & ELECOM & MexElec & OtherG & DISTRB & FINBU & PERS & NONMAR & Average \\
\hline AUS & 0.909 & 0.933 & 0.767 & 0.818 & 0.878 & 0.743 & 0.776 & 0.832 \\
AUT & 0.944 & 0.986 & 0.945 & 0.926 & 0.949 & 0.799 & 0.830 & 0.911 \\
CZE & 0.739 & 0.814 & 0.641 & 0.648 & 0.644 & 0.609 & 0.528 & 0.660 \\
DEN & 0.858 & 0.858 & 0.842 & 0.832 & 0.901 & 0.705 & 0.739 & 0.819 \\
FIN & 0.984 & 0.986 & 0.754 & 0.833 & 1.000 & 0.705 & 0.676 & 0.848 \\
ITA & 0.885 & 0.968 & 0.862 & 0.848 & 0.754 & 0.910 & 0.998 & 0.889 \\
NET & 0.876 & 0.990 & 0.902 & 0.971 & 0.863 & 0.857 & 0.853 & 0.902 \\
POR & 0.877 & 0.973 & 0.959 & 0.908 & 0.888 & 0.717 & 0.768 & 0.870 \\
SPA & 0.927 & 0.904 & 0.950 & 0.790 & 0.959 & 0.988 & 0.796 & 0.902 \\
SWE & 0.818 & 0.881 & 0.779 & 0.880 & 0.944 & 0.881 & 0.974 & 0.879 \\
UK & 0.959 & 0.949 & 0.874 & 0.962 & 0.834 & 0.845 & 0.760 & 0.884 \\
US & 0.983 & 0.956 & 0.760 & 0.993 & 0.994 & 0.987 & 0.805 & 0.925 \\
\hline Average & 0.897 & 0.933 & 0.836 & 0.867 & 0.884 & 0.812 & 0.792 & 0.860 \\
\hline
\end{tabular}

* The highest and lowest scores are highlighted.

\footnotetext{
${ }^{9}$ Despite of the Czech Republic's short history as a capitalist country, it is one of the 34 IMF-defined 'Advanced Economies' like the others in the sample. The group of 34 Advanced Economies, classified by the IMF, includes Australia, Austria, Belgium, Canada, Cyprus, Czech Republic, Denmark, Estonia, Finland, France, Germany, Greece, Hong Kong SAR, Iceland, Ireland, Israel, Italy, Japan, Korea, Luxembourg, Malta, Netherlands, New Zealand, Norway, Portugal, Singapore, Slovak Republic, Slovenia, Spain, Sweden, Switzerland, Taiwan Province of China, United Kingdom, and United States. Source: http://www.imf.org/external/pubs/ft/weo/2011/02/weodata/weoselagr.aspx\#a110 September 2013)
} 
In the second stage of the empirical analysis, we relate the estimate of productive efficiency to inputs, taking into account their qualities (this was not part of the measurement of productive efficiency, as the quality of an input is assumed to be the same for all sectors in all countries).

To analyze how the differences in the proportion of migrant workers in the labour force affect the productive efficiency given the other qualities of the inputs we apply the regression model formalized by:

$$
\ln \mathrm{PE}_{\mathrm{it}}=\alpha+\gamma_{1} \mathrm{D} 1_{\mathrm{it}} \mathrm{FL}_{\mathrm{it}}+\ldots+\gamma_{7} \mathrm{D}_{\mathrm{it}} \mathrm{FL}_{\mathrm{it}}+\beta_{1} \ln \mathrm{LW}_{\mathrm{it}}+\beta_{2} \ln \mathrm{KW}_{\mathrm{it}}+\mathrm{u}_{\mathrm{it}}
$$

where:

$$
\begin{aligned}
& \mathrm{Dk}_{\mathrm{it}}=1 \text { for sector } \mathrm{k} \text { and } 0 \text { otherwise }(\mathrm{k}=1, . .7) \text {, } \\
& \mathrm{FL}_{\mathrm{it}}=\text { the proportion of migrant workers out of all high-skilled (or medium-to- } \\
& \text { high skilled) workers (\%), } \\
& \mathrm{LW}_{\mathrm{it}}=\text { quality of all labour input measured by labour compensation per unit of } \\
& \quad \text { labour, } \\
& \mathrm{KW}_{\mathrm{it}}=\text { quality of all capital input measured by capital compensation per unit } \\
& \quad \text { of capital stock, } \\
& \ln (.)=\text { the natural logarithm, and } \mathrm{u}_{\mathrm{it}} \text { is the random error term } \\
& \text { for } \mathrm{i}=1, . ., 84 \text { ( } 7 \text { sectors for } 12 \text { countries), and } \mathrm{t}=1999,2000 \text { and } 2001 .
\end{aligned}
$$

Of our main interest are whether the $\gamma$ coefficients are significantly different from zero or not, and if significant what their signs are. If the composition of the labour force, apart from different skill levels as are represented by unit labour compensation, is important for productivity, then the $\gamma$ coefficients will be significant. The effect could be in either direction. The $\beta$ coefficients are the productivity elasticity with respect to the quality of labour and capital inputs. 
A complication with the PE variable in a regression analysis is that it is censored at 1 , and hence its $\log$ at 0 , from above. To overcome this problem, the PE scores of 1 are recomputed after excluding the inputs and output of the corresponding DMU from the $\mathrm{X}$ and $\mathrm{Y}$ matrices in the DEA problem (3). This allows the PE scores for the DMU to be higher than 1 implying that the DMU is 'super-efficient'. This approach has a useful advantage over the popular Tobit-model approach in that the former enables discrimination of super-efficient DMUs while the latter does not, resulting in the estimates based on the former approach being more efficient. ${ }^{10}$

The model was firstly estimated with sector dummy variables as well as their interaction with FL. However, their coefficients turned out to be jointly insignificant leading to the above model with their interactions with FL only.

Two versions of the model are estimated with two alternative definitions of FL - one as the proportion of migrant workers out of all high-skilled workers (Model 1) and the other as the proportion of migrant workers out of all medium-to-high skilled workers (Model 2). Both models had significant evidence of heteroscedasticity with the pvalues of the Breusch-Pagan tests being close to zero. Hence, the models are estimated with the feasible generalised least-squares (FGLS) method while assuming the following variance function.

$\ln \mathrm{V}\left(\mathrm{u}_{\mathrm{it}}\right)=\alpha_{0}+\alpha_{1} \mathrm{D} 1_{\mathrm{it}} \mathrm{FL}_{\mathrm{it}}+\ldots+\alpha_{7} \mathrm{D}_{\mathrm{it}} \mathrm{FL}_{\mathrm{it}}+\alpha_{8} \operatorname{lnL\mathrm {W}_{\mathrm {it}}}+\alpha_{9} \ln \mathrm{KW}_{\mathrm{it}}+\mathrm{v}_{\mathrm{it}}$

Table 5 reports the FGLS estimation results with the standard errors and asymptotic p-values provided in parentheses and square brackets respectively.

The two sets of results are almost the same. The only significant differences are that the coefficients for $\mathrm{FL}_{\mathrm{O} \text { therG }}$ and $\mathrm{FL}_{\mathrm{NONMAR}}$ become significant at $5 \%$ when the proportion of medium-to-high skilled migrant workers is used, and that the order of the sizes of the coefficients for $\mathrm{FL}_{\mathrm{OtherG}}$ and $\mathrm{FL}_{\mathrm{DISTR}}$ riB reverses. All the coefficients

\footnotetext{
10 This approach was introduced by Andersen and PAtersen (1993).
} 
except those for $\mathrm{FL}_{\mathrm{OtherG}}$ and $\mathrm{FL}_{\text {NONMAR }}$ in Model 1 are significant at 5\%. The null hypothesis that all $\gamma$ coefficients are jointly equal to zero is strongly rejected by both models, implying that the proportion of skilled migrant workers is an important factor in determining productivity. The null hypothesis that all the $\gamma$ coefficients are the same has also been strongly rejected, implying that the effect of migrant skilled workers on the productivity varies across sectors. 
Table 5: FGLS Estimation Results

\begin{tabular}{|c|c|c|}
\hline & $\begin{array}{c}\text { Model 1: } \\
\text { High-Skilled }\end{array}$ & $\begin{array}{c}\text { Model 2: } \\
\text { Medium-to-High Skilled }\end{array}$ \\
\hline ELECOM & $\begin{array}{c}0.0011 \\
(0.0004) \\
{[0.012]^{\#}}\end{array}$ & $\begin{array}{c}0.0015 \\
(0.0006) \\
{[0.009]}\end{array}$ \\
\hline MexElec & $\begin{array}{c}0.0042 \\
(0.0016) \\
{[0.012]}\end{array}$ & $\begin{array}{c}0.0054 \\
(0.0019) \\
{[0.005]}\end{array}$ \\
\hline OtherG & $\begin{array}{c}0.0050 \\
(0.0026) \\
{[0.052]}\end{array}$ & $\begin{array}{c}0.0060 \\
(0.0026) \\
{[0.021]}\end{array}$ \\
\hline DISTRB & $\begin{array}{c}0.0048 \\
(0.0010) \\
{[0.000]}\end{array}$ & $\begin{array}{c}0.0088 \\
(0.0016) \\
{[0.000]}\end{array}$ \\
\hline FINBU & $\begin{array}{c}-0.0048 \\
(0.0010) \\
{[0.000]}\end{array}$ & $\begin{array}{c}-0.0056 \\
(0.0011) \\
{[0.000]}\end{array}$ \\
\hline PERS & $\begin{array}{c}0.0040 \\
(0.0009) \\
{[0.000]}\end{array}$ & $\begin{array}{c}0.0054 \\
(0.0011) \\
{[0.000]}\end{array}$ \\
\hline NONMAR & $\begin{array}{c}0.0032 \\
(0.0017) \\
{[0.063]}\end{array}$ & $\begin{array}{c}0.0049 \\
(0.0020) \\
{[0.014]}\end{array}$ \\
\hline $\ln \mathrm{LW}$ & $\begin{array}{c}0.2239 \\
(0.0190) \\
{[0.000]}\end{array}$ & $\begin{array}{c}0.2299 \\
(0.0187) \\
{[0.000]}\end{array}$ \\
\hline $\ln K W$ & $\begin{array}{c}0.1336 \\
(0.0079) \\
{[0.000]}\end{array}$ & $\begin{array}{c}0.1356 \\
(0.0074) \\
{[0.000]} \\
\end{array}$ \\
\hline $\begin{array}{l}\text { Sample Size } \\
\text { Buse } \mathrm{R}^{2} \\
\text { Chi-square (7) statistic for all } \gamma \\
\quad \text { coefficients }=0 \\
\text { Chi-square (6) statistic for } \\
\quad \text { identical } \gamma \text { coefficients }\end{array}$ & $\begin{array}{c}240^{*} \\
0.696 \\
78.11 \\
{[0.000]} \\
71.74 \\
{[0.000]}\end{array}$ & $\begin{array}{c}240 \\
0.722 \\
97.50 \\
{[0.000]} \\
93.44 \\
{[0.000]}\end{array}$ \\
\hline
\end{tabular}

\#: Standard errors are in parentheses and asymptotic p-values are in square brackets.

*: The 12 observations for ELECOM and MexElec of Italy and U.S. are excluded as data on migrant workers for those sectors are not available.

The proportion of skilled migrant workers has a positive effect on the productive efficiency for all sectors except the Finance \& Business sector, where the effect is negative. This outcome reveals that skilled migrants contribute positively to their host 
countries' productive efficiency. The effect on the productivity of a one percentage point change in the proportion of medium-to-high skilled migrant workers (Model 2) is by far the largest for the Distribution sector (0.88\%), while the effect of a change in the proportion of high-skilled migrant workers (Model 1) is the largest for the Other Production sector only by a small margin ( $0.50 \%$ versus $0.48 \%)$.

The $\gamma$-coefficient estimates for the Distribution sector in the two models imply that an increase in the proportion of high-skilled migrant workers by one percentage point leads to a $0.5 \%$ increase in the productivity, while an increase in the proportion of medium-to-high skilled migrant workers leads to a $0.88 \%$ increase, ceteris paribus. The smallest positive effect occurs for the Electrical \& Communication sector, where one percentage point increases in the proportions of high-skilled and medium-to-high skilled migrant workers lead to increases in productivity by $0.11 \%$ and $0.15 \%$ respectively. In contrast, an increase in the proportion of migrant workers out of skilled workers has a negative effect for the Finance \& Business sector, where a one percentage point increase leads to $0.48 \%$ and $0.56 \%$ decreases in the productivity for Model 1 and Model 2 respectively.

To help understand the reasons for this opposite effect of migrant workers on productivity, Figure 1 presents the average values of some key figures about labour input in each sector. 
Figure 1: Key Figures about Labour Input (sectoral averages)

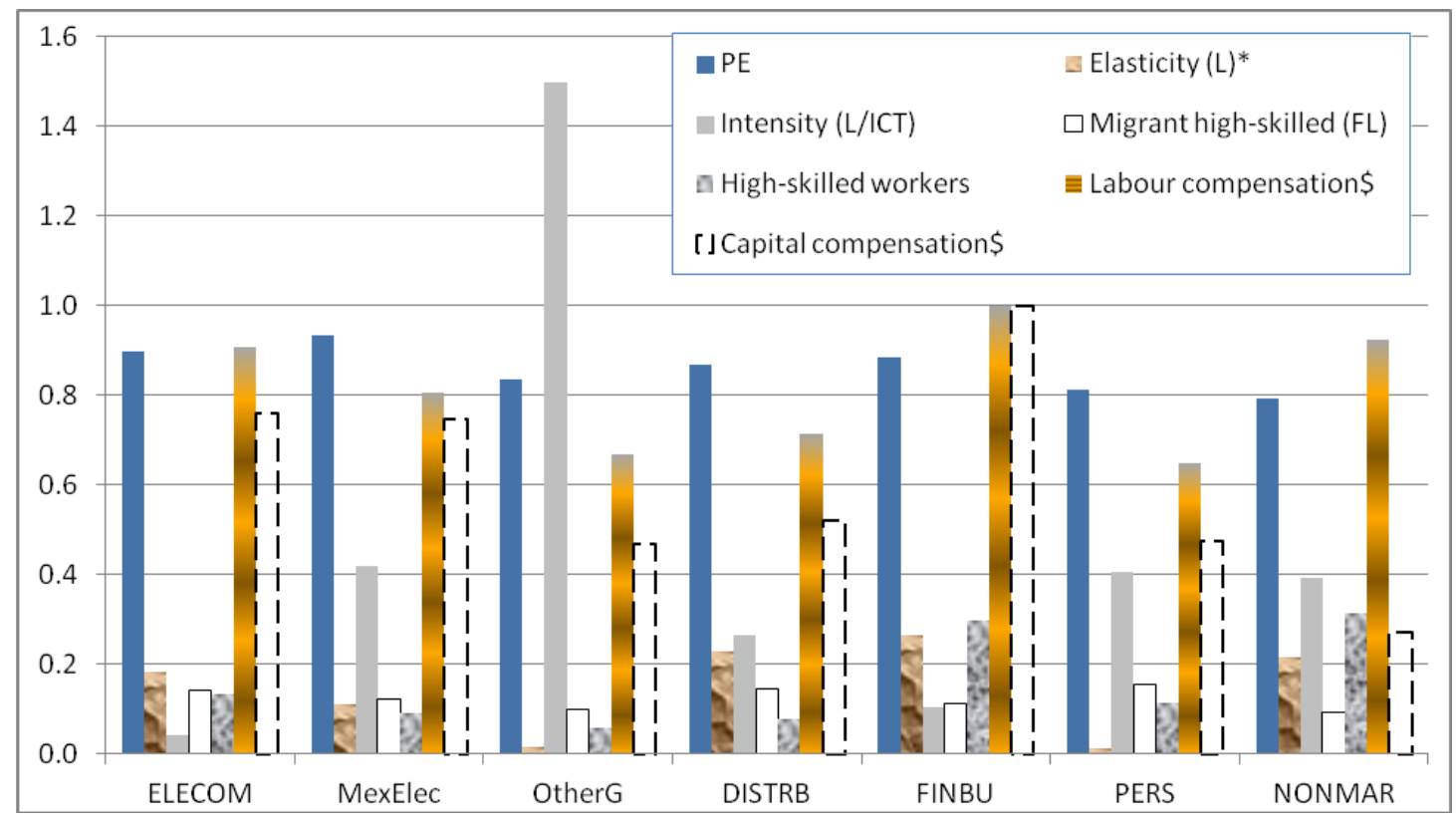

*: The elasticity of output with respect to labour input, which is estimated as the coefficient for the log of labour input in a CobbDouglas production function. The eight production functions, one for each sector plus one for the whole economy, are estimated as an SUR model.

\$: Scaled.

What makes the Finance \& Business sector unique is that the elasticity of output with respect to (quality-unadjusted) labour input is the highest (0.263), implying that its labour force is the most productive among the sectors. This fact is reinforced by that it has the second highest proportion of high-skilled workers (0.297), only next to the Non-Market sector (0.315). It also has the second lowest labour intensity relative to ICT capital (0.105), suggesting high substitution elasticity of labour for capital and hence high productivity of labour. All these are consistent with labour compensation per unit that is the highest among sectors as it reflects the quality of labour input. The highest quality of capital input in the same sector, represented by its capital compensation, further enhances the productivity of its labour input.

On the other hand, the two sectors that have the largest $\gamma$ coefficients, the OtherProduction and Distribution sectors, do not seem to have many features in common. The Other Production sector has the highest labour intensity (1.498), but the Distribution sector has relatively low labour intensity (0.263). The Other Production 
sector has the second lowest labour elasticity (0.015), while the Distribution sector has the second highest $(0.230)$. The only conspicuous features common in both sectors are that the proportions of high-skilled workers out of all workers are the lowest (0.057 and 0.079 for OtherG and DISTRB respectively) and consequently the lowest labour compensation levels except for the Personal Service sector.

A clear picture emerging from these analyses is that skilled migrant workers are more productive than average skilled workers in most sectors, where the lower the level of skill of general workers in the sector the higher the contribution of additional skilled migrant workers to improving the productivity. However, in the Finance \& Business sector, where the skill level of average worker is the highest among sectors, the skill level of average skilled migrant worker is lower than that of general average skilled worker, and hence the higher the proportion of migrant workers the lower the productivity.

There could be many reasons why migrant workers' skill level is not as high as the general skill level in the Finance \& Business sector. One of the obvious reasons is that it includes industries where entrance is most competitive, resulting in the best workers ending up working in the industries. Another possible reason is that migrant workers' knowledge about the business environment and rules, including the language, may fall short of that of native skilled workers in a sector that is often characterised by cutthroat competition (e.g. Peri and Sparber, 2008; Chiswick and Taengnoi, 2007).

Finally, the elasticity of productivity with respect to labour compensation is almost twice that with respect to capital compensation (0.22\% versus $0.13 \%)$. It implies that, on average, enhancing the quality of labour input is much more effective than enhancing the quality of capital input in improving productive efficiency. 


\section{Conclusions and Implications for Policymakers}

The empirical results suggest that skilled migrants are both desirable and valuable in enhancing a host country's productive efficiency. Introducing a skill-biased immigration policy appears therefore justified on the basis that skilled migrants make a positive contribution to efficiency, and the result is statistically robust to changes in model specification.

It is however important to highlight that Australia, the only country with an explicit labour-market driven approach to migration, does not stand out as the host country where skilled immigrants make the largest contribution to efficiency, as the interaction variables combining skilled migrants with county dummies yield coefficients that are seldom statistically significant. Other relevant forces are therefore at play, first and foremost institutional differences amongst host countries.

Recent research has pointed out that the emphasis on skilled migration may contribute to the higher incidence of over-education in the host country's labour market. It has been estimated that about $40 \%$ of immigrants to Australia perform jobs that require a lower level of education than that possessed. Similar figures exist for domestic labour markets in Canada and New Zealand as well as the European Union. Immigration policy matters in selecting applicants but it is the labour market that determines the success of the immigration policy in place.

Our results support the side of the debate calling for a skill-biased approach to immigration policy, especially for countries where income inequalities do not act as a natural screening device (Roy, 1951; Borjas, 1987). However, issues about immigrants' social inclusion, participation, and success ultimately depend on how efficient a country's labour market is in granting access to opportunities and in rewarding the human capital supplied. A skill-biased immigration policy may contribute to the well-functioning of the domestic labour market, but it cannot per se 
solve issues connected with the most efficient utilisation of skilled labour and the resources available.

\section{References}

Andersen, Per, and Niels Chritian Petersen. 1993. “A Procedure for Ranking Efficient Units in Data Envelopment Analysis.” Management Science 39 (10): 12611264.

Antecol, H., D. A. Cobb-Clark, and S. J. Trejo. 2003. "Immigration Policy and the Skills of Immigrants to Australia, Canada, and the United States.” Journal of Human Resources 38(1): 192-218.

Beach, C. M., A. G. Green, and C. Worswick. 2007. "Impacts of the Point System and Immigration Policy Levers on Skill Characteristics of Canadian Immigrants.” Research in Labor Economics 27: 349-401.

Belot, M. V., and T. J. Hatton. 2012. "Immigrant Selection in the OECD." The Scandinavian Journal of Economics 114 (4): 1105-1128.

Borjas, G. J. 1987. "Self-selection and the Earnings of Immigrants." American Economic Review 77: 531-553.

Borjas, G. J. 1991. Immigration policy, national origin, and immigrant skills: A comparison of Canada and the United States (No. w3691). National Bureau of Economic Research.

Charnes, A., W. W. Cooper, and E. Rhodes. 1978. "Measuring the Efficiency of Decision Making Units.” European Journal of Operational Research 2 (6): $429-444$.

Chiswick, B. R., and S. Taengnoi. 2007. "Occupational Choice of High Skilled Immigrants in the United States.” International Migration 45 (5): 3-34.

Deprins, Dominique, Leopold Simar, and Henry Tulkens. 1984. "Measuring LaborEfficiency in Post Offices.” in The Performance of Public Enterprises: Concepts and Measurement, Studies in Mathematical and Managerial Economics Series 33, edited by M. Marchand, P. Pestieau, and H. Tulkens, 243-267. Amsterdam: North-Holland.

Dolton, P., and A. Vignoles. 2000. "The incidence and effects of overeducation in the U.K. graduate labour market.” Economics of Education Review 19: 179-198.

Färe, Rolf, and Daniel Primont. 1995. Multi-Output Production and Duality: Theory and Applications. Boston: Kluwer Academic Publishers. 
Farrell, M. J. 1957. “The Measurement of Productive Efficiency.” Journal of the Royal Statistical Society Series A Volume 120 Part III: 253-281.

Green, Alan G., and David A. Green. 1995. "Canadian Immigration Policy: The Effectiveness of the Point System and Other Instruments.” Canadian Journal of Economics 28: 1006-1041.

Huber, P., M. Landesmann, C. Robinson, and R. Stehrer. 2010. "Migrants' Skills and Productivity: a European Perspective.” National Institute Economic Review 213 (1): R20-R34.

Hunt, J., and M. Gauthier-Loiselle. 2008. "How Much Does Immigration Boost Innovation?” National Bureau of Economic Research Working Papers 14312.

Kler, P. 2007. “A panel data investigation into overeducation among tertiary educated Australian immigrants.” Journal of Economic Studies 34(3): 179-193.

Inklaar, R., and M. Timmer. 2008. “GGDC Productivity Level Database: International Comparison of Output, Inputs and Productivity at the Industry Level.” EU KLEMS Working Paper Series 40.

Jorgenson, Dale W., and Marcel P. Timmer. 2011. "Structural Change in Advanced Nations: A New Set of Stylized Facts.” Scandinavian Journal of Economics 113 (1): 1-29.

Kangasniemi, M., M. Mas, C. Robinson, and L. Serrano. 2012. "The Economic Impact of Migration: Productivity Analysis for Spain and the UK.” Journal of Productivity Analysis 38: 333-343.

Lewis, E. 2011. "Immigration, Skill Mix and the Capital-Skill Complementarity.” Quarterly Journal of Economics 126(2): 1029-1069.

Miller, P. W. 1999. "Immigration Policy and Immigrant Quality: The Australian Points System.” American Economic Review 89 (2): 192-197.

Paserman, M.D. 2013. “Do High-Skill Immigrants Raise Productivity? Evidence from Israeli Manufacturing Firms, 1990-1999.” IZA Journal of Migration 2:6.

Peri, G., and C. Sparber. 2008. "Task Specialisation, Immigration and Wages.” Centro Studi Luca d'Agliano Development Studies Working Paper 252.

Roy, A. D. 1951. "Some Thoughts on the Distribution of Earnings.” Oxford Economic Papers 3(2): 135-146.

Timmer, M., T. van Moergastel, E. Stuivenwold, G. Ypma, M. O’Mahony, and M. Kangasniemi. 2007. EU KLEMS Growth and Productivity Accounts, Version 1.0, Part I Methodology. EU KLEMS 
Winkelmann, R. 1999. “Immigration: The New Zealand Experience.” IZA Discussion Paper Series No. 61.

Zimmermann, K., T. K. Bauer, and M. Lofstrom. 2000. "Immigration Policy, Assimilation of Immigrants and Natives' Sentiments towards Immigrants: Evidence from 12 OECD-Countries.” IZA Discussion Paper series No. 187. 
Table A.1: Definitions of the Variables and Sources of Data

\begin{tabular}{|c|c|c|c|c|c|c|}
\hline \multirow{2}{*}{ Variable } & \multirow{2}{*}{$\begin{array}{l}\text { Unit of } \\
\text { Variable }\end{array}$} & \multicolumn{4}{|c|}{ Raw Series } & \multirow{2}{*}{ Comment } \\
\hline & & Code & Description & Unit & Source $^{1}$ & \\
\hline Output & $\begin{array}{l}\text { volumn in } \\
\text { millions }\end{array}$ & GO & $\begin{array}{l}\text { Gross output at current } \\
\text { basic prices }\end{array}$ & $\$ M$ & output_09I_alt & $\begin{array}{l}\text { Converted to the real volumn by dividing } \\
\text { by US_GO_P \& PPP. }\end{array}$ \\
\hline Intermediate Input & $\begin{array}{l}\text { volumn in } \\
\text { millions }\end{array}$ & II & $\begin{array}{ll}\begin{array}{l}\text { Intermediate } \\
\text { current }\end{array} & \begin{array}{l}\text { inputs at } \\
\text { prices }\end{array} \\
\end{array}$ & $\$ M$ & output_09I_alt & $\begin{array}{l}\text { Converted to the real volumn by dividing } \\
\text { by US_II_P \& PPP }\end{array}$ \\
\hline Labour & $\begin{array}{l}\text { million } \\
\text { hours }\end{array}$ & H_EMP & $\begin{array}{l}\text { Total hours worked by } \\
\text { persons engaged }\end{array}$ & $\begin{array}{l}\text { million } \\
\text { hours }\end{array}$ & output_09I_alt & \\
\hline ICT Capital & $\begin{array}{l}\text { volumn in } \\
\text { millions }\end{array}$ & K_ICT & $\begin{array}{l}\text { ICT assets (real fixed } \\
\text { capital stock) }\end{array}$ & $\begin{array}{l}\text { millions in } \\
1995 \text { price }\end{array}$ & capital_09l & 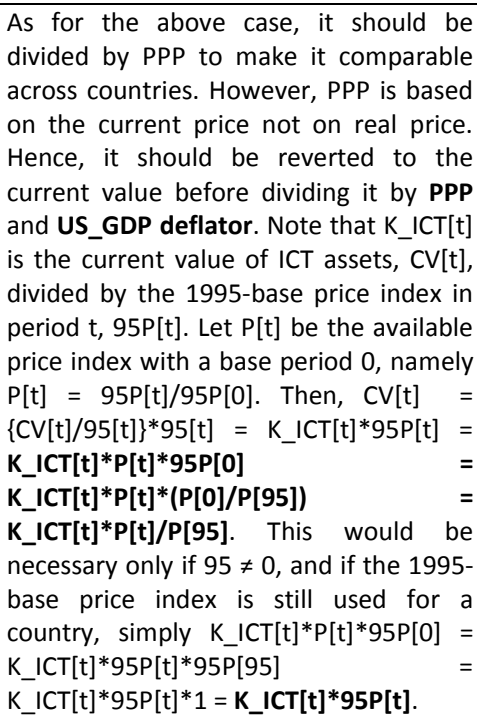 \\
\hline NonICT Capital & $\begin{array}{l}\text { volumn in } \\
\text { millions }\end{array}$ & K_NonICT & $\begin{array}{l}\text { Non-ICT assets (real } \\
\text { fixed capital stock) }\end{array}$ & $\begin{array}{l}\text { millions in } \\
1995 \text { price }\end{array}$ & capital_09I & as above \\
\hline
\end{tabular}

Variables for Regression Analysis

\begin{tabular}{|c|c|c|c|c|c|c|}
\hline \multirow{2}{*}{ Variable } & \multirow{2}{*}{$\begin{array}{l}\text { Unit of } \\
\text { Variable }\end{array}$} & \multicolumn{4}{|c|}{ Raw Series } & \multirow{2}{*}{ Comment } \\
\hline & & Code & Description & Unit & Source $^{1}$ & \\
\hline $\begin{array}{l}\text { Proportion of Migrant } \\
\text { Workers in MS \& HS }\end{array}$ & $\%$ & ISCED $3 / 4 \& 5 / 6$ & $\begin{array}{l}\text { ISCED } \\
\text { (secondary level), } \\
\text { ISCED 5/6 (tertiary } \\
\text { level); Native and } \\
\text { Foreign Born }\end{array}$ & $\begin{array}{l}\text { Persons } \\
\text { employed }\end{array}$ & $\begin{array}{l}\text { OECD } \\
\text { Migration } \\
\text { Statistics, } \\
\text { Immigrants }^{2} \\
\text { by Sector }\end{array}$ & $\begin{array}{l}\text { Foreign-born MS \& HS employees / (All } \\
\text { MS \& HS employees) }\end{array}$ \\
\hline $\begin{array}{l}\text { Share of MS \& HS Labour } \\
\text { Input }\end{array}$ & $\%$ & H_MS, H_HS & $\begin{array}{l}\text { Share of Total } \\
\text { Hours Worked by } \\
\text { Medium \& High } \\
\text { Skilled Persons } \\
\text { Engaged }^{4}\end{array}$ & $\%$ & $\begin{array}{l}\text { output_alt__ } \\
081\end{array}$ & H_MS + H_HS \\
\hline Quality of Capital Inputs & $\begin{array}{l}\text { real price } \\
\text { per } 1000 \\
\text { units of } \\
\text { capital } \\
\text { input }\end{array}$ & CAP & $\begin{array}{l}\text { Capital } \\
\text { compensation }\end{array}$ & $\$ M$ & $\begin{array}{l}\text { output_09I_ } \\
\text { alt }\end{array}$ & $\begin{array}{l}\text { Converted to the real price per } 1000 \\
\text { units of capital input as } 1000^{*} \text { CAP/(ICT } \\
\text { capital + NonICT capital) and then } \\
\text { divided by PPP \& US_GDPdeflator. }\end{array}$ \\
\hline R\&D Expenditure & $\begin{array}{l}\text { PPP } 2005 \\
\$ b\end{array}$ & GB.XPD.RSDV.GD.ZS & $\begin{array}{l}R \text { \& D Expenditure } \\
\text { as \% of GDP }\end{array}$ & $\%$ of GDP & $\begin{array}{l}\text { The World } \\
\text { Bank - } \\
\text { World } \\
\text { Developme } \\
\text { nt } \\
\text { Indicators } \\
(5 \quad \text { May } \\
2011)^{3}\end{array}$ & \\
\hline
\end{tabular}


Variables Used for Conversion of Raw Series

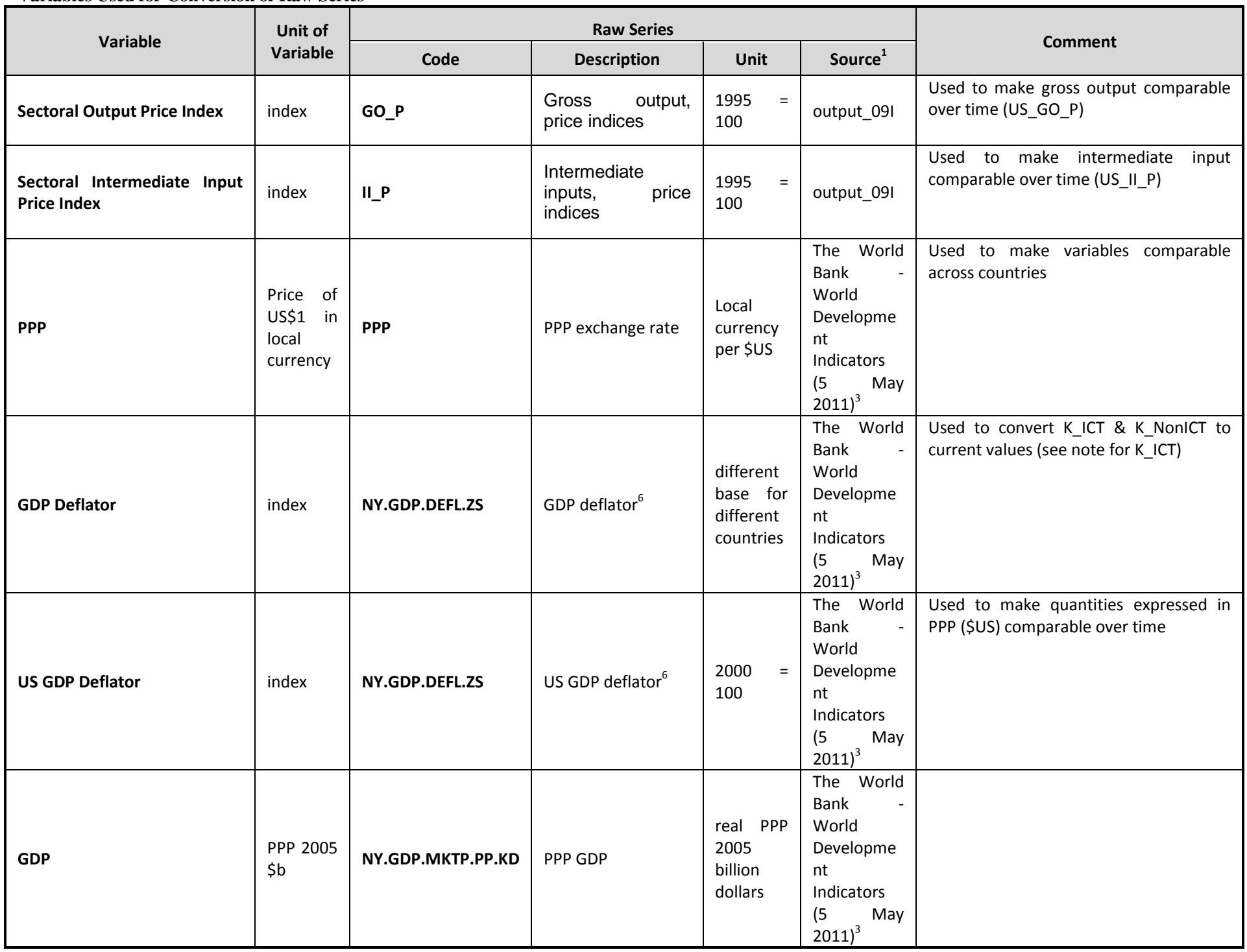

Reference Variables

\begin{tabular}{|c|c|c|c|c|c|c|}
\hline \multirow{2}{*}{ Variable } & \multirow{2}{*}{$\begin{array}{c}\text { Unit of } \\
\text { Variable }\end{array}$} & \multicolumn{4}{|c|}{ Raw Series } & \multirow{2}{*}{ Comment } \\
\hline & & Code & Description & Unit & Source $^{1}$ & \\
\hline DTFP & & VAConTFP & $\begin{array}{l}\text { Contirbution of TFP } \\
\text { to VA change }\end{array}$ & $\%$ & $\begin{array}{l}\text { output_09I_ } \\
\text { alt }\end{array}$ & $\begin{array}{l}\text { Contribution of TFP to value added } \\
\text { growth (percentage points) }\end{array}$ \\
\hline
\end{tabular}

1. EU KLEMS database (euklems.net) unless stated otherwise.

For US, naics_output_09I_alt_rev \& usa-naics_capital_09Irev. Also, used sic_labour_input_08I for H_MS and H_HS.

For POR(tugal), ouput_alt_08I for DTFP, TFP and captial_08I for KICT \& KNICT.

2. stats.oecd.org

3. data.worldbank.org

4. Definitions slightly vary across countries. See Table 5.3 of Timmer et al. (2007) for detailed definitions.

5. Interpolated (AUS 99, 01, 03; DEN 00, SWE 98, 00, 02)

6. All countries' deflators are converted to a 1995-based series by $\mathrm{P}[\mathrm{t}] / \mathrm{P}[95]$ 
Table A.2: Data for DEA Analysis

(3-year average: 1999,2000, and 2001)

\begin{tabular}{|c|c|c|c|c|c|c|c|c|}
\hline & $\mathrm{ALL}^{*}$ & ELECOM & MexElec & OtherG & DISTR & FINBU & PERS & NONMAR \\
\hline \multicolumn{7}{|l|}{ OUTPUT } & \multicolumn{2}{|c|}{ US\$m (2000) } \\
\hline AUS & 957,182 & 45,079 & 180,694 & 169,846 & 184,743 & 145,020 & 55,502 & 167,146 \\
\hline AUT & 367,830 & 27,465 & 95,348 & 45,262 & 68,280 & 41,959 & 24,740 & 65,240 \\
\hline CZE & 354,761 & 33,230 & 122,249 & 59,495 & 57,546 & 30,437 & 15,659 & 39,171 \\
\hline DEN & 237,699 & 15,720 & 49,886 & 29,811 & 51,567 & 27,366 & 12,237 & 50,864 \\
\hline FIN & 227,034 & 31,822 & 68,567 & 25,123 & 35,526 & 17,834 & 10,026 & 41,928 \\
\hline ITA & $2,638,923$ & 156,849 & 825,189 & 263,740 & 551,597 & 301,944 & 169,372 & 382,108 \\
\hline NET & 826,513 & 52,230 & 196,100 & 110,349 & 143,923 & 137,547 & 43,590 & 140,375 \\
\hline POR & 305,746 & 19,137 & 82,342 & 48,719 & 50,545 & 32,215 & 20,080 & 51,224 \\
\hline SPA & $1,516,754$ & 84,067 & 449,054 & 235,717 & 235,634 & 139,466 & 139,693 & 222,815 \\
\hline SWE & 419,784 & 42,966 & 116,387 & 30,582 & 68,772 & 52,923 & 19,849 & 91,689 \\
\hline UK & $2,594,081$ & 191,974 & 523,272 & 303,419 & 470,771 & 449,838 & 179,499 & 472,138 \\
\hline US & $16,062,295$ & $1,359,724$ & $3,338,528$ & $1,384,168$ & $2,311,766$ & $2,800,066$ & 991,628 & $3,833,274$ \\
\hline average & $2,209,050$ & 171,689 & 503,968 & 225,519 & 352,556 & 348,051 & 140,156 & 463,164 \\
\hline s.d. & $4,448,395$ & 378,242 & 923,286 & 378,302 & 640,181 & 783,188 & 275,501 & $1,070,561$ \\
\hline c.v. & 2.01 & 2.20 & 1.83 & 1.68 & 1.82 & 2.25 & 1.97 & 2.31 \\
\hline \multicolumn{7}{|c|}{ INTERMEDIATE INPUT } & \multicolumn{2}{|c|}{ US\$m (2000) } \\
\hline AUS & 518,765 & 21,262 & 129,420 & 101,326 & 96,423 & 74,669 & 31,277 & 56,185 \\
\hline AUT & 179,529 & 14,346 & 62,960 & 23,720 & 28,503 & 17,316 & 10,570 & 21,025 \\
\hline CZE & 227,976 & 20,997 & 93,414 & 42,584 & 26,500 & 18,466 & 9,538 & 16,041 \\
\hline DEN & 118,794 & 8,276 & 33,300 & 16,429 & 25,813 & 13,080 & 5,756 & 14,900 \\
\hline FIN & 122,764 & 17,392 & 48,478 & 14,799 & 14,526 & 7,523 & 5,245 & 15,312 \\
\hline ITA & $1,447,239$ & 85,076 & 608,101 & 153,049 & 289,506 & 137,273 & 83,376 & 84,290 \\
\hline NET & 450,565 & 31,429 & 145,348 & 70,853 & 61,199 & 68,838 & 23,667 & 46,217 \\
\hline POR & 167,685 & 10,536 & 60,988 & 31,499 & 22,529 & 14,988 & 11,124 & 14,449 \\
\hline SPA & 807,715 & 44,802 & 330,803 & 140,825 & 101,176 & 61,408 & 60,350 & 61,178 \\
\hline SWE & 227,061 & 28,502 & 80,277 & 14,933 & 32,062 & 25,043 & 10,537 & 36,315 \\
\hline UK & $1,389,816$ & 98,236 & 343,145 & 187,929 & 223,823 & 244,496 & 89,937 & 189,280 \\
\hline US & $7,480,431$ & 642,915 & $2,200,448$ & 705,565 & 833,906 & $1,206,091$ & 501,067 & $1,349,419$ \\
\hline average & $1,094,862$ & 85,314 & 344,724 & 125,293 & 146,331 & 157,433 & 70,204 & 158,718 \\
\hline s.d. & $2,065,207$ & 177,936 & 608,808 & 192,444 & 233,465 & 337,324 & 139,037 & 378,188 \\
\hline c.v. & 1.89 & 2.09 & 1.77 & 1.54 & 1.60 & 2.14 & 1.98 & 2.38 \\
\hline \multicolumn{7}{|c|}{ LABOUR INPUT } & \multicolumn{2}{|c|}{ million hours } \\
\hline AUS & 16,423 & 461 & 2,063 & 2,653 & 3,808 & 2,399 & 1,698 & 3,341 \\
\hline AUT & 6,725 & 241 & 1,002 & 1,016 & 1,437 & 823 & 762 & 1,445 \\
\hline CZE & 10,031 & 473 & 2,386 & 1,761 & 2,138 & 929 & 702 & 1,641 \\
\hline DEN & 4,289 & 165 & 649 & 471 & 892 & 499 & 341 & 1,271 \\
\hline FIN & 4,008 & 188 & 632 & 717 & 749 & 366 & 304 & 1,053 \\
\hline ITA & 42,714 & 1,355 & 8,106 & 5,930 & 9,480 & 5,011 & 6,121 & 6,711 \\
\hline NET & 11,614 & 345 & 1,471 & 1,438 & 2,549 & 2,285 & 1,091 & 2,435 \\
\hline POR & 9,286 & 181 & 1,777 & 2,397 & 1,885 & 581 & 1,072 & 1,392 \\
\hline SPA & 28,253 & 704 & 4,789 & 5,419 & 5,899 & 2,657 & 3,823 & 4,961 \\
\hline SWE & 7,052 & 291 & 1,206 & 760 & 1,284 & 834 & 561 & 2,116 \\
\hline UK & 47,345 & 1,918 & 6,891 & 5,159 & 9,980 & 8,625 & 5,003 & 9,769 \\
\hline US & 269,310 & 11,070 & 34,776 & 25,761 & 52,256 & 45,435 & 28,713 & 71,298 \\
\hline average & 38,088 & 1,449 & 5,479 & 4,457 & 7,696 & 5,870 & 4,183 & 8,953 \\
\hline s.d. & 74,288 & 3,077 & 9,553 & 6,985 & 14,392 & 12,690 & 7,968 & 19,812 \\
\hline c.v. & 1.95 & 2.12 & 1.74 & 1.57 & 1.87 & 2.16 & 1.91 & 2.21 \\
\hline \multicolumn{7}{|c|}{ ICT CAPITAL INPUT } & \multicolumn{2}{|c|}{ US\$়m (2000) } \\
\hline AUS & 91,351 & 11,681 & 9,038 & 10,194 & 15,913 & 20,307 & 6,094 & 18,122 \\
\hline AUT & 30,036 & 10,719 & 3,032 & 802 & 4,571 & 6,860 & 1,451 & 2,601 \\
\hline CZE & 37,774 & 10,835 & 4,289 & 3,219 & 7,020 & 6,980 & 1,221 & 4,211 \\
\hline DEN & 28,366 & 2,203 & 3,116 & 1,236 & 6,158 & 8,970 & 2,563 & 4,120 \\
\hline FIN & 17,453 & 2,917 & 2,558 & 958 & 3,857 & 3,215 & 1,435 & 2,514 \\
\hline ITA & 188,822 & 26,207 & 26,598 & 6,166 & 66,543 & 37,634 & 8,629 & 17,045 \\
\hline NET & 78,055 & 13,279 & 7,847 & 3,798 & 12,548 & 23,635 & 3,622 & 13,326 \\
\hline POR & 26,575 & 4,871 & 855 & 222 & 2,336 & 6,243 & 3,693 & 8,356 \\
\hline SPA & 116,408 & 16,045 & 16,412 & 4,971 & 34,252 & 21,087 & 11,149 & 12,493 \\
\hline SWE & 33,332 & 6,469 & 7,253 & 1,042 & 6,186 & 8,827 & 1,551 & 2,004 \\
\hline UK & 277,762 & 82,895 & 26,232 & 9,780 & 37,468 & 81,464 & 14,887 & 25,039 \\
\hline US & $2,142,787$ & 524,451 & 195,331 & 90,619 & 337,091 & 690,173 & 35,129 & 269,994 \\
\hline average & 255,727 & 59,381 & 25,213 & 11,084 & 44,495 & 76,283 & 7,619 & 31,652 \\
\hline s.d. & 599,457 & 148,071 & 54,298 & 25,278 & 94,125 & 194,535 & 9,707 & 75,423 \\
\hline c.v. & 2.34 & 2.49 & 2.15 & 2.28 & 2.12 & 2.55 & 1.27 & 2.38 \\
\hline
\end{tabular}




\begin{tabular}{|l|r|r|r|r|r|r|r|r|}
\hline & \multicolumn{1}{|c|}{ ALL } & \multicolumn{1}{|c|}{ ELECOM } & \multicolumn{1}{c|}{ MexElec } & \multicolumn{1}{c|}{ OtherG } & \multicolumn{1}{c|}{ DISTR } & \multicolumn{1}{c|}{ FINBU } & \multicolumn{1}{|c|}{ PERS } & \multicolumn{1}{c|}{ NONMAR } \\
\hline \multicolumn{1}{|c|}{ NonICT CAPITAL INPUT $(2000)$} \\
\hline AUS & $1,455,679$ & 48,689 & 85,214 & 265,922 & 194,165 & 74,477 & 55,308 & 774,061 \\
AUT & 770,661 & 11,755 & 58,033 & 90,075 & 80,069 & 25,785 & 42,196 & 462,749 \\
CZE & 703,895 & 19,609 & 91,980 & 101,160 & 124,635 & 27,301 & 30,775 & 308,435 \\
DEN & 543,712 & 13,219 & 30,638 & 55,607 & 47,848 & 9,830 & 17,226 & 369,344 \\
FIN & 373,217 & 10,262 & 35,132 & 40,561 & 50,024 & 3,631 & 12,786 & 220,822 \\
ITA & $4,947,324$ & 103,839 & 628,058 & 494,222 & 384,765 & $2,377,484$ & 142,658 & 816,298 \\
NET & $1,495,420$ & 35,867 & 94,531 & 139,156 & 123,757 & 79,633 & 30,133 & 992,343 \\
POR & 422,530 & 10,541 & 50,895 & 37,056 & 58,077 & 18,879 & 14,928 & 232,155 \\
SPA & $2,849,714$ & 40,082 & 286,458 & 230,134 & 300,809 & 58,152 & 92,251 & $1,841,826$ \\
SWE & 492,645 & 23,631 & 59,280 & 66,707 & 69,902 & 18,862 & 12,489 & 241,774 \\
UK & $3,373,708$ & 66,900 & 255,864 & 347,665 & 297,809 & 157,299 & 166,526 & $2,081,646$ \\
US & $22,425,811$ & 878,566 & $1,429,909$ & $2,383,689$ & $1,669,908$ & $1,003,434$ & 585,693 & $14,474,613$ \\
\hline average & $3,321,193$ & 105,247 & 258,833 & 354,330 & 283,481 & 321,231 & 100,247 & $1,901,339$ \\
s.d. & $6,185,266$ & 245,125 & 406,648 & 654,527 & 451,209 & 704,743 & 161,405 & $4,008,128$ \\
c.v. & 1.86 & 2.33 & 1.57 & 1.85 & 1.59 & 2.19 & 1.61 & 2.11 \\
\hline
\end{tabular}

*: The figures for ALL sectors are slightly different from the sum of sectoral figures because price indices (GO_P) used in the conversion of nominal values to real volumes are different from sector to sector. (Source of the raw data: EU KLEMS) 